
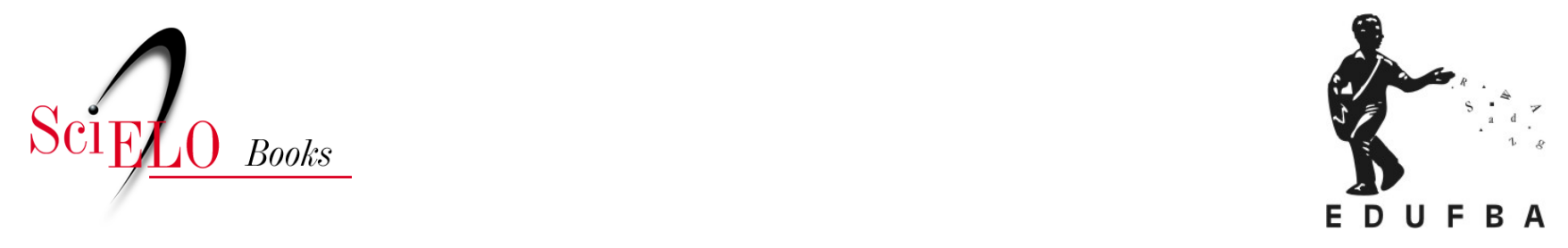

\title{
Inserção da saúde bucal no programa saúde da família
}

\author{
Thais Regis Aranha Rossi
}

\section{SciELO Books / SciELO Livros / SciELO Libros}

ROSSI, T.R.A. Inserção da saúde bucal no programa saúde da família. In: Produção social das políticas de saúde bucal no Brasil [online]. Salvador: EDUFBA, 2018, pp. 155-178. ISBN 978-85-232-2022-8. https://doi.org/10.7476/9788523220228.0008.

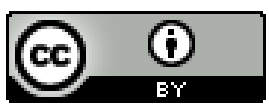

All the contents of this work, except where otherwise noted, is licensed under a Creative Commons Attribution 4.0 International license.

Todo o conteúdo deste trabalho, exceto quando houver ressalva, é publicado sob a licença Creative Commons Atribição 4.0. 


\section{INSERÇÃO DA SAÚDE BUCAL NO PROGRAMA SAÚDE DA FAMÍLIA}

O Programa Saúde da Família (PSF) foi instituído em dezembro de 1993, baseado em algumas experiências exitosas municipais que estavam em curso no Brasil. (BRASIL, 2012) A implantação do Programa é um marco na incorporação das estratégias de atenção primária no sistema de saúde brasileiro, preconizando mudanças no âmbito organizacional do modelo de atenção vigente. (ESCOREL et al., 2007)

A inclusão da saúde bucal na saúde da família ocorreu em 2000, na gestão de Sônia Maria Dantas de Souza, com forte articulação das entidades de classe com deputados e da Federação Interestadual dos Odontologistas (FIO) e apoio da coordenação e diretoria do Departamento de Atenção Básica. O Boletim da entidade retrata a luta empreendida para a chamada "vitória histórica da Odontologia" em 2000.

O primeiro registro de tentativa de inclusão foi em abril de 1994, quando Swendenberger do Nascimento Barbosa, então presidente da FIO, entregou documento reivindicando a inserção da saúde bucal no recém-criado PSF ao ministro da Saúde Henrique Santilho. O movimento foi apoiado pelas Secretarias Municipais de Saúde de Curitiba e Maceió, da Secretaria Estadual de São Paulo, da Fundação Nacional de Saúde assim como pelos professores Paulo Capel Narvai, da USP, e Jorge Cordón, da UnB. (BOLETIM DA FEDERAÇÃO INTERESTADUAL DOS ODONTOLOGISTAS, 2000)

Há divergências nos discursos quanto à inclusão na agenda. Segundo a gestora da Coordenação de Saúde Bucal (Cosab), em 1995, buscou-se inserir uma pauta na agenda do Ministério da Saúde, através da Atenção Básica, sobre a inclusão da saúde bucal no PSF, mas não se obteve êxito. Desta forma, passou a ocupar-se de outros temas relevantes como a fluoretação das águas e o inquérito epidemiológico. Já gestores que atuavam no Departamento de Atenção Básica 
(DAB) afirmaram que a inclusão da ESB no Programa foi pautada pelos profissionais que atuavam no $\mathrm{DAB}$ devido à experiência exitosa de projetos pilotos em municípios, o que gerou um chamamento para que a Cosab atuasse neste sentido. A inclusão da saúde bucal na equipe mínima foi justificada no DAB pela especificidade do objeto de trabalho que não poderia ser reproduzido pelo(a) médico(a) ou enfermeiro(a).

No ano de 1996, foram realizados o levantamento da situação das águas de abastecimento público no país e lançado o livro Fluoretação das águas: Manual de orientação prática, de autoria de Osvaldo Carro Buendia. ${ }^{87} \mathrm{O}$ livro foi oriundo de cooperação técnica com as Nações Unidas e abordava considerações gerais sobre o flúor, concepção de cárie, informações técnicas para fluoretação das águas com distintos materiais e em localidades como zonas rurais, escolas e, por fim, tratava da análise do teor residual do flúor e de como realizar as compras por órgãos públicos, com vistas à fluoretação das águas. (BUENDIA, 1996)

Ainda no ano de 1996, realizou-se o segundo inquérito epidemiológico em Saúde Bucal, dez anos após a realização do primeiro inquérito epidemiológico. O levantamento foi desenhado por consultores da Cosab, como o prof. João Antônio Caminha e obteve o apoio dos CRO, ABO e Secretarias Estaduais de Saúde. O inquérito recebeu muitas críticas quanto à fidedignidade dos seus dados, como problemas no plano amostral e critérios, dentre outros. Essas críticas foram discutidas no XIV Enatespo em Fortaleza (CE). (OLIVEIRA, 1998) O trabalho pesquisou apenas cárie dentária em escolares de 6 a 12 anos, em zona urbana de 27 capitais e do Distrito Federal. A pesquisa mostrou tendência de redução da cárie dentária na população escolar com CPO-D de 3,06 aos 12 anos quando comparado ao CPO-D de 6,65 em 1986, na mesma idade, e persistência das desigualdades regionais.

No ano seguinte, em outubro de 1997, foi lançado um documento no qual os esforços estiveram voltados, novamente, para as práticas de saúde bucal na saúde da família, desta vez direcionada para o Agente Comunitário de Saúde (ACS). (BRASIL, 1997) O manual seguia a política praticada no Ministério desenvolvida pelo DAB e buscava orientar o ACS em algumas situações específicas relaciona-

87 Osvaldo Carro Buendia era membro do grupo de especialistas em Prevenção das Doenças Bucais e consultor para Assistência à Fluoretação de Águas da CNSB do Ministério da Saúde. Foi secretário geral do Grupo Estadual de Controle da Fluoretação de Águas do Estado de São Paulo (Gecof-SP), da Secretaria de Estado da Saúde, sediado no Centro de Apoio ao Desenvolvimento da Assistência à Saúde Escolar. Professor titular de Odontologia Preventiva e Social do curso de Odontologia da Universidade Santo Amaro (UNISA), em São Paulo. Cirurgião-dentista sanitarista formado pela Faculdade de Saúde Pública da USP. (BUENDIA, 1996) 
das a doenças bucais, mas, também, era direcionado a ações educativas e preventivas.

O documento elencava dois grupos de atividades a serem desenvolvidas pelos ACS:

- educação/prevenção em saúde bucal; e

- detecção de problemas e encaminhamento adequado.

O primeiro grupo foi constituído por três atividades: educação em Saúde Bucal sobre as causas das principais doenças que afligem a cavidade bucal, consumo inteligente de açúcar, higiene bucal e autoexame; escovação supervisionada e bochechos fluorados. Já o segundo grupo tratava do encaminhamento de casos de odontalgias, hemorragias, abcessos, fraturas dentárias e ósseas, cavidades de cárie, sangramento gengival, lesões de mucosa e fendas palatinas/lábio leporino aos serviços de saúde. (BRASIL, 1997)

De acordo com o documento, o ACS seria responsável por explicar as principais doenças que atingem a cavidade bucal e os cuidados necessários para a sua prevenção. Outra função seria orientar os membros da família quanto à limpeza dos dentes e o uso de fio dental. Ademais, deveriam realizar escovações supervisionadas e bochechos fluorados com orientação de equipes odontológicas. Entretanto, o documento não retratou os aspectos operacionais de implementação da proposta. (BRASIL, 1997)

Ainda em 1997, no mês de outubro, foi publicada a Portaria que instituía o Comitê Técnico Científico (CTC) de assessoramento à Coordenação de Saúde Bucal constituído por João Antônio Neto Caminha, professor adjunto do Departamento de Odontologia Preventiva e Social da UFRGS; Jayme Aparecido Cury, professor titular de Bioquímica da Faculdade de Odontologia de Piracicaba (FOP)/UNICAMP; Djalmo Sanzi Souza, chefe da Divisão de Saúde Comunitária do Grupo Hospitalar Conceição; Paulo Capel Narvai, professor doutor da FSP/USP; e Sylvio Palermo Gevaerd, professor assistente de Odontologia Preventiva e Social da UFPR. A coordenadora Sônia Dantas foi atribuída a Secretaria Executiva do CTC. Paulo Capel Narvai foi votado e escolhido como representante para o CTC no XIII Enatespo, ocorrido no mesmo ano.

A escolha dos nomes para o Comitê Técnico Científico se baseou na expertise para os temas de fluoretação - Jayme Cury, Sistema de Informação; João Antônio Caminha Neto, Saúde Coletiva; Paulo Capel, Djalmo Sanzi e Sylvio Gevaerd. ${ }^{88}$

Segundo Sonia Maria Dantas de Souza, em entrevista à autora. 
Assim como as outras comissões constituídas anteriormente, de acordo com os entrevistados, o CTC trabalhava nas pautas elencadas pela coordenação, sem autonomia para a inclusão de outros temas. Ademais, os membros também representavam a coordenação em alguns debates, como Sylvio Gevaerd, nas discussões com a Agência Nacional de Saúde Suplementar (ANS); Antônio Caminha participou da elaboração de um Sistema de Informações em Saúde Bucal, específico, com procedimentos de Odontologia, que não foi implementado pelo Ministério da Saúde.

As discussões sobre a inclusão da saúde bucal no PSF continuaram a fazer parte dos Enatespo. O relatório final do XIV Enatespo, realizado em Fortaleza (CE), de 9 a 13 de agosto de 1998, apontava que a inclusão da saúde bucal na saúde da família deveria ser incentivada sem prejuízo das equipes existentes nas redes de serviços. Referia, também, o potencial da estratégia de mudança do modelo de atenção vigente. (ENATESPO, 1998)

No relatório final do Encontro, foi registrada moção de repúdio à coordenadora nacional de Saúde Bucal, afirmando que a profissional não representava o posicionamento dos trabalhadores do setor e referia, também, que ela era contrária ao desenvolvimento e fortalecimento do SUS. (ENATESPO, 1998)

No mesmo evento, ocorrido no ano seguinte, o XV Enatespo, realizado no período de 26 a 30 de setembro de 1999, no Rio de Janeiro (RJ), também se destacou a importância da referida inclusão, pois programas como o PACS e o PSF possibilitavam "[...] ir além das estratégias tradicionais restritas a determinados espaços sociais, ao privilegiar como local de atuação o território e a família”. (ENATESPO, 1999, p. 2) A plenária final reconheceu e afirmou a importância da inclusão dos profissionais da Odontologia que são o cirurgião-dentista, o auxiliar de Consultório Dentário, à época, hoje com a denominação de auxiliar em Saúde Bucal, e o técnico de Higiene Dental, atualmente técnico em Saúde Bucal, nas equipes do PSF. Ademais, foi recomendada a implementação de incentivo no PAB aos municípios que realizavam ações de saúde bucal no PACS ou no PSF. Paulo Capel Narvai e Djalmo Sanzi Souza participaram da relatoria do XV Enatespo. (ENATESPO, 1999)

O Boletim da FIO (1999) destacava a defesa do Enatespo pela inclusão de profissionais de Odontologia no PSF, não apenas o CD, mas, também, os auxiliares e técnicos, tendo a entidade sido representada no evento por José Carrijo Brom. A Federação também fez articulações em prol da inserção do projeto na agenda governamental. Segundo o Entrevistado 33, aliaram-se ao CFO, professores univer- 
sitários, a exemplo de Paulo Capel Narvai e Paulo Frazão, assim como pessoas do serviço, além do apoio de parlamentares.

A FIO, através da sua presidente Rozangela Camapum, juntamente com as entidades de classe, como o CFO, representado por Miguel Nobre, fizeram a articulação política com parlamentares que demandavam audiência com o Ministro da Saúde e apresentavam seu pleito. Também participaram do movimento pela inclusão da saúde bucal, a ABO, Conselhos Regionais de Odontologia, Academia Brasileira de Odontologia. Muitas vezes, a FIO orientava o CFO nas articulações políticas. Outras entidades que também participaram deste processo foram a Federação Nacional dos Odontologistas (FNO), através de sua vice-presidente, a cirurgiã-dentista Joana Batista Oliveira Lopes, e a ABO, representada pelo cirurgião-dentista dr. Norberto Francisco Lubiana.

O CTC foi convocado para elaboração da proposta de inclusão da saúde bucal na saúde da família. Membros do comitê estiveram à frente da concepção do documento, como Djalmo Sanzi Souza, Paulo Capel Narvai e Sylvio Palermo Gevaerd. O documento passou por algumas revisões e versões, tendo sofrido mudanças ao longo do processo de pactuações. O primeiro esboço da proposta data de abril de 2000; a primeira revisão do documento com memória de cálculo, de agosto do mesmo ano; e a última versão, próxima daquela publicada em Portaria, em outubro de 2000 (Quadro 14). Entretanto, dentre alguns aspectos não planejados no âmbito do CTC, o principal não aceito pelo ministro foi a paridade entre equipe de saúde da família e saúde bucal. Neste mesmo ano, a Cosab passou a se denominar Área Técnica de Saúde Bucal (ATSB) devido a mudanças na estrutura do Ministério da Saúde.

As coordenações estaduais também foram convocadas para discutir a proposta a fim de relatar suas experiências no Programa de Saúde da Família. Existiam muitos municípios com experiências exitosas (CALADO, 2002), contudo, em muitos estados brasileiros, as experiências estavam em seu início ou sequer haviam iniciado.

Outro fato se somou aos esforços do CTC, da coordenação da ATSB, às manifestações através dos Enatespo, da frente de articulação da FIO com o CFO e outras entidades odontológicas, pela publicação da PNAD do IBGE. Em julho de 2000, o ministro da Saúde, dr. José Serra, declarou seu interesse em estudar a inclusão do dentista no PSF, a partir dos resultados da PNAD que apontava o quantitativo de 30 milhões de brasileiros sem acesso aos serviços odontológicos no Brasil. (TRINTA..., 2000) 
As enfermeiras Heloisa Machado e Maria Fatima de Sousa que exerciam a gestão da Atenção Básica no Ministério da Saúde apoiaram a entrada da saúde bucal no PSF. Os três documentos de formulação da entrada da saúde bucal no PSF apresentam distinções. O primeiro documento, de abril de 2000, apresentava três modalidades: a primeira de adesão transitória de capacitação dos ACS para desenvolver ações voltadas à educação em saúde com ênfase na saúde bucal; a segunda seria uma etapa intermediária, apenas com o cirurgião-dentista na equipe mínima; e a terceira modalidade, denominada de adesão avançada, contaria com a equipe completa de saúde bucal, o CD, o ACD e o THD. A partir da segunda proposta, de agosto de 2000, a etapa de adesão é suprimida e a modalidade intermediária inclui o ACD, ficando a modalidade avançada com a equipe completa (Quadro 14). (BRASIL, 2000a, 2000b, 2000d).

Na terceira proposta, de outubro de 2000 , mais próxima do texto que consta na Portaria $\mathrm{n}^{\circ} 267$, de 6 de março de 2001, publicada no DOU em 7 de março de 2001, constam as modalidades I e II com a supressão dos termos intermediária e avançado. Quanto à redação dos objetivos, na Portaria publicada constam: melhorar as condições de saúde bucal da população brasileira; orientar as práticas de atenção à saúde bucal, consoante ao preconizado pelo PSF; assegurar o acesso progressivo de todas as famílias residentes nas áreas cobertas pelas equipes de saúde da família às ações de promoção e de prevenção bem como àquelas de caráter curativo-restauradoras de saúde bucal; capacitar, formar e educar permanentemente os profissionais de saúde bucal necessários ao PSF, por intermédio da articulação entre as instituições de ensino superior e as de serviço do SUS; e avaliar os padrões de qualidade e o impacto das ações de saúde bucal desenvolvidas, de acordo com os princípios do PSF. (BRASIL, 2000a, 2000b, 2000d) 


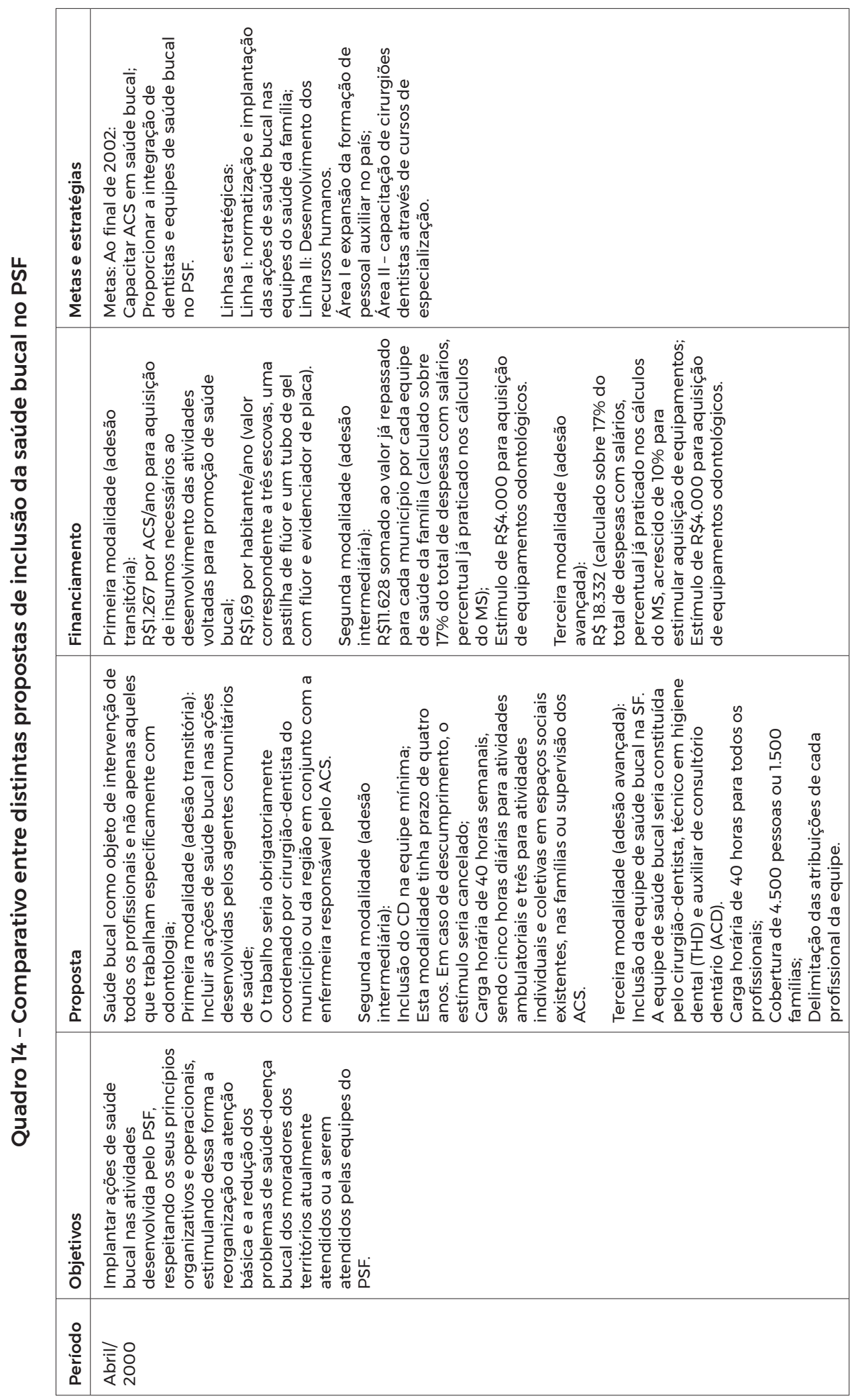




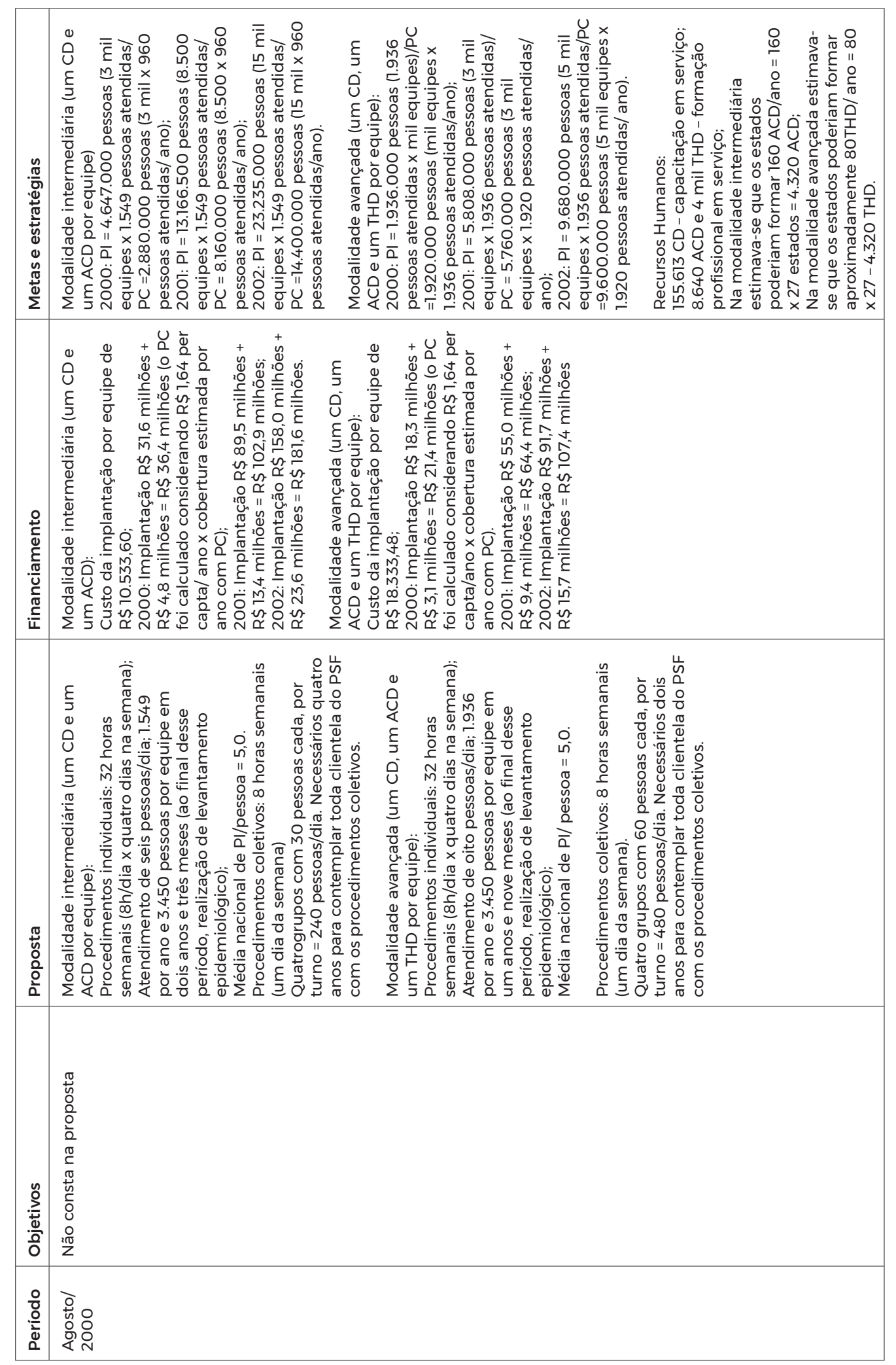




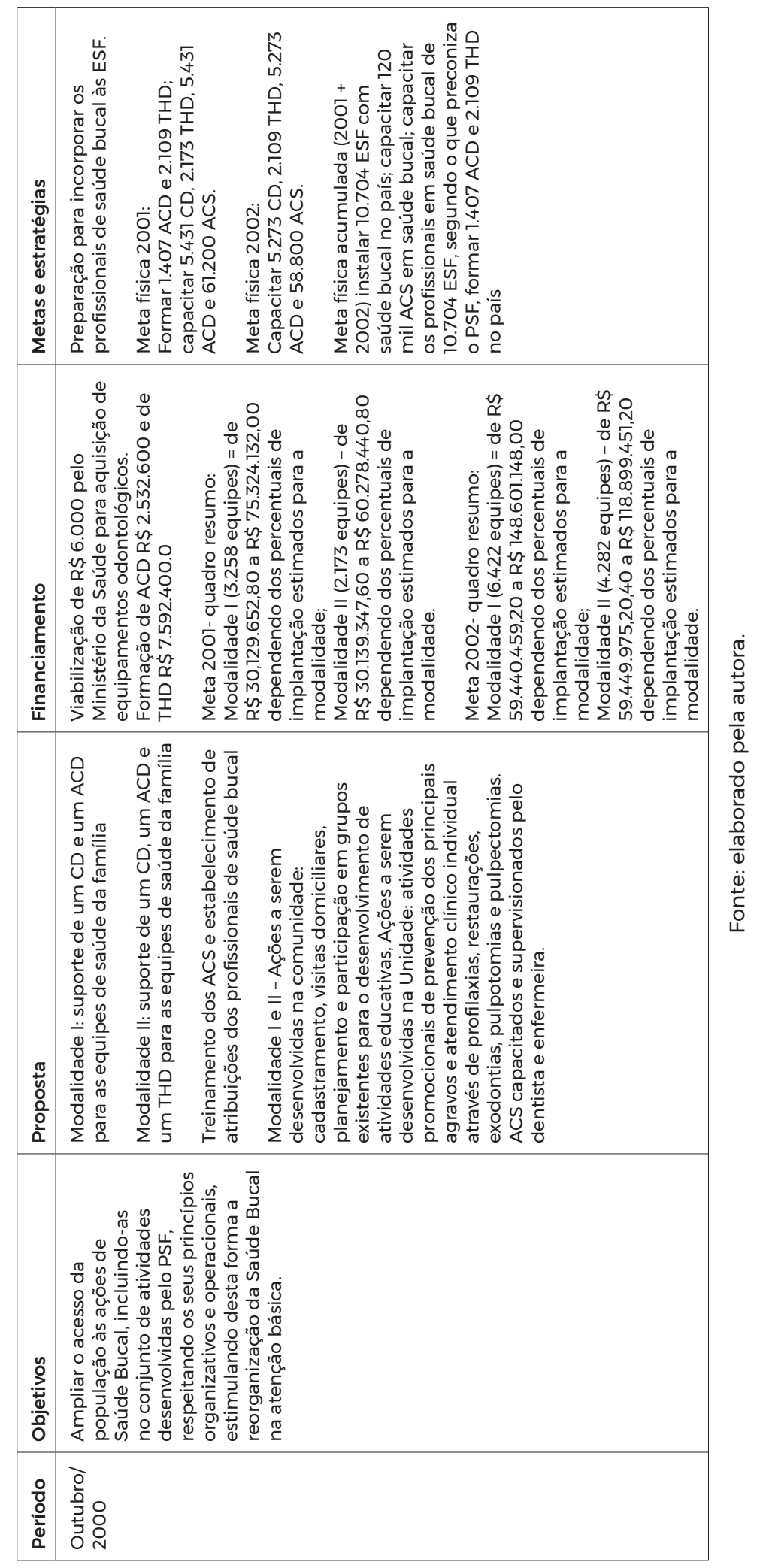

Produção Social da Políticas de Saúde Bucal no Brasil / 163 
Na primeira versão, não havia clareza acerca dos meios operacionais para a capacitação do ACD e do THD. Na segunda e terceira propostas, a etapa relativa ao ACS é incorporada no programa, mas não contando como uma fase. Quanto ao financiamento, nas duas últimas versões, observou-se maior detalhamento dos cálculos sobre procedimentos coletivos e individuais, entretanto, nas três versões, manteve-se o cálculo sobre o salário dos profissionais e valores de referência utilizados pelo Ministério da Saúde. Em nenhuma das três propostas sugere-se a implantação de uma equipe de saúde bucal para duas de saúde da família, conforme chancelado em Portaria oficial. (BRASIL, 2000a, 2000b, 2000d)

A articulação das entidades que mobilizaram parlamentares no sentido de influenciar na decisão de inclusão da saúde bucal no PSF, assim como o papel exercido pelos Enatespo foram de fundamental importância. Os Entrevistados 33 e 34 atribuem ao movimento das entidades o papel decisivo.

Nesse sentido, aponta-se papel importante desempenhado pelas entidades de classe ao interior no campo político, em discordância dos estudos de Garcia (2006) que afirma a ausência de demanda externa ao MS significativa e Rendeiro (2011) que apontara o protagonismo dos burocratas nesse processo. Outro trabalho também aponta que as entidades de classe e os Enatespo atuaram com relevância neste processo (NARVAI, 2011), assim como os achados do presente estudo.

O CTC, formado por dentistas com maior capital científico oriundos das universidades, também foi de fundamental importância no processo. Os gestores da atenção básica apoiavam a entrada da saúde bucal no PSF. A coordenadora da ATSB vinha lutando contra as propostas de até quatro equipes de saúde da família para uma de saúde bucal feitas pela alta administração do Ministério. A gestora buscava apoio e respaldo nas pessoas que compunham seu comitê. O processo de lutas ao interior do Ministério da Saúde foi intenso, com muitas idas e vindas da coordenação de ATSB, com diversos cálculos e tentativas de propostas para a alta administração. O secretário de Políticas de Saúde, Cláudio Duarte da Fonseca, foi o interlocutor no processo de negociação que culminou na aceitação da proposta de uma equipe de saúde bucal (ESB) para duas equipes de saúde da família (ESF).

[...] eu e o secretario discutíamos horas exaustivas e ele não aceitava. Mandava a gente refazer com outro cenário. Nós saímos oito horas da noite, daí íamos sentar refazer as continhas e no outro dia nós íamos [...] nós não queríamos essa questão de dois para um, a nossa proposta era a inclusão do dentista. Então ele começou a aderir assim quatro dentistas para uma equipe, faça as contas. [...] Ele começou faça dois dentistas, faça três dentistas, voltávamos, fazíamos conta. - [...] Quando ele disse quatro dentistas, eu lhe disse: eu não vou fazer. Ele disse: - então é pegar 
ou largar. Eu disse: - dessa vez eu largo. [...] Ele falou vamos fechar em três, eu tenho x e vou fechar em três. Eu disse, então vamos fazer o seguinte, eu vou voltar para sala, vou ligar para o meu comitê e vou conversar com eles. Porque eu também precisava de um respaldo do meu comitê e vou ligar para o CFO, para ABO. Aí foi aquele rebuliço, nem pensar. [...] Voltei no outro dia, às oito horas da manhã do outro dia. [...] Depois desse apelo emocionante, ele levantou, me abraçou e disse: - está bom, me ganhou, duas equipes, pronto. Porque uma ele não aceitava uma [equipe] de jeito nenhum. [...] Então foi assim, liguei para o comitê: - olha duas equipes, modalidade I, modalidade II, agora venham para cá. Mandei passagem para todo mundo, venham para cá, vamos agora sentar, vamos alinhavar, vamos começar isso aqui. ${ }^{89}$

Em uma das reuniões de pactuação das entidades odontológicas e da coordenação da ATSB com o ministro José Serra, ele anunciou ao então presidente do Conselho Federal de Odontologia a proposta de uma ESB x duas ESF, obtendo a aprovação dos presentes.

O Serra é meio duro assim, e eu insistindo né, aí ele olhou pra mim e disse: 'então tá doutor pela sua insistência então dois pra um', eu digo: 'como dois pra um?', 'Duas equipes pra um dentista', ai eu disse: 'tá fechado!', aí estendi a mão e tá fechado. Aí quando eu sai alguns me queimaram: 'você aceitou? Os médicos têm um para um e nós termos dois'. Eu digo: 'bom, tem que começar por algum lugar'. [... $]^{90}$

Assim, em 25 de outubro de 2000, dia no qual se celebra o Dia do Dentista, foi anunciada oficialmente a inclusão da saúde bucal na saúde da família pelo ministro José Serra. As entidades odontológicas e a coordenação de saúde bucal participaram do ato. A foto que estampava a capa do Jornal da FIO não apresentava a descrição dos participantes na celebração, mas cita-se, ao centro, o ministro José Serra, a seu lado direito a dra. Sônia Dantas, a seu lado esquerdo dr. Miguel Nobre, então presidente do CFO, dra. Rozangela Camapum da FIO, dr. Francisco Lubiana, então presidente da $\mathrm{ABO}$. Os membros do CTC não participaram da cerimônia pois não concordavam com a proporção de duas ESF para uma ESB, afirmavam que esta proporção não modificaria o modelo assistencial vigente.

Foram publicadas duas portarias relativas à inclusão da equipe de saúde bucal. A primeira, a Portaria ${ }^{\circ} 1.444$, de 28 de dezembro de 2000, publicada no DOU, de 29 de dezembro de 2000, que estabelecia o incentivo financeiro para a reorga- 
nização da atenção à saúde bucal por meio do PSF. (BRASIL, 2000d) A publicação oficial estabelecia o repasse anual de $\mathrm{R} \$ 13.000$ para equipe da modalidade I (CD + ACD) e R $\$ 16.000$ para a modalidade II (CD + THD + ACD), com repasses mensais fundo a fundo de 1/12 avos. Ademais, fixava o incentivo de $\mathrm{R} \$ 5.000$ para aquisição de equipamentos odontológicos. Cada equipe de saúde bucal deveria atender a 6.900 habitantes e sua implantação deveria obedecer à proporção de duas ESF para uma ESB, sendo que os municípios com menos de 6.900 habitantes poderiam implantar uma ESB para uma ou duas ESF. A segunda portaria, a já mencionada Portaria ${ }^{\circ} 267$, de 6 de março de 2001, publicada no DOU, em 7 de março de 2001, regulamentava o ato anterior. (BRASIL, 2001) Nesta Portaria são traçadas as estratégias para a mudança no modelo de atenção pretendida. Ela se baseou no documento elaborado pelos consultores e definiu as bases para reorientação das ações, a incorporação da equipe de saúde bucal, as atribuições de cada um dos profissionais, inclusive do ACS, as responsabilidades institucionais e o financiamento. (BRASIL, 2001)

O fato foi celebrado por distintos motivos, pelas entidades odontológicas e pela coordenação da ATSB, entretanto, esta sofreu muitas críticas, tanto pela ausência da paridade entre ESB e ESF como pelo próprio atraso na inclusão da saúde bucal no PSF e pela forma como se realizou a inclusão. As críticas foram realizadas por membros do comitê e que participavam dos Enatespo, além das entidades de classe.

Se conseguiu foi um dinheiro novo. Esse mérito tem. Só que com quatro anos de atraso. O que significa esses quatro anos de atraso? Significa que a maioria dos dentistas não participaram do processo de territorialização garantiu o pontapé inicial da criação vinculo usuário-comunidade-equipe. A proporção dois por um é absurda, nenhum dentista dá conta de seis mil, sete mil pessoas, é impossível na atenção primária de qualidade, organizada, com programação adequada, com indicadores epidemiológicos ou sem indicadores mas com um mínimo, mínimo de avaliação epidemiológica [...]. Então esses quatro anos de atraso parece que é pouco na origem do processo mas nos causou problemas. (Entrevistado 7, dentista, consultor)

Outro membro do Comitê, Paulo Capel Narvai, comentou a reação do ministro Serra e também criticou a inclusão tardia da saúde bucal no PSF.

A reação do ministro da Saúde aos dados sobre acesso à assistência odontológica no Brasil causou, entre muitas lideranças odontológicas, impacto 
maior do que os números que a motivaram. Refiro-me, especificamente, ao termo 'abismado' - utilizado por José Serra ao comentar as informações contidas no relatório da PNAD-1998 (Pesquisa Nacional por Amostra de Domicílios), publicado pelo IBGE em agosto de 2000. Não foram poucos os que reclamaram do 'desconhecimento' e da 'ignorância' da principal autoridade pública do setor em relação à desassistência odontológica e ao elitismo do acesso. Sentar na cadeira do dentista continua sendo monopólio de classe social no Brasil. Insuportável privilégio, diga-se - mais uma cruel expressão das iniquidades que nos assolam. [...] Num lampejo, talvez não tenha tido tempo de filtrar seus sentimentos, formulando uma resposta 'politicamente correta' - coisa que, aliás, fez logo em seguida, anunciando a 'inclusão de dentistas nas equipes do programa de saúde da família', uma prioridade da pasta que comanda. Os dados a que me refiro foram amplamente noticiados: dentre os brasileiros, 29,6 milhões (18,7\% da população) nunca foram ao dentista. A porcentagem sobe para $32 \%$ na área rural. (NARVAI, 2000, p. 1)

Manfredini (2006) apontou a ausência de movimentos populares com demandas por serviços odontológicos ou organizações de usuários cariados ou portadores de doenças periodontais ou na luta por próteses dentárias no processo de construção das políticas de saúde bucal. Citou outros trabalhos que defenderam a inserção da SB no PSF como um processo que não refletiu a compreensão das ações de SB na atenção básica, as dificuldades inerentes ao processo de trabalho, a ausência de uma discussão ampla com a participação dos profissionais e não baseada em experiências existentes.

O Jornal do CFO ressaltou, em 2000, ofício enviado ao ministro que enfatizava o grande problema de concentração de profissionais nos grandes centros urbanos e o excessivo número de faculdades de Odontologia no país como fatores para os dados alarmantes da PNAD. (SAÚDE..., 2000) O Jornal da ABO - Seção Rio de Janeiro também festejou a nova opção de mercado de trabalho para o CD. (CALADO, 2002)

A inclusão da equipe de saúde bucal no PSF representou uma grande alternativa de mercado de trabalho para o cirurgião-dentista. $O$ alto número de profissionais recém-formados que adentra o mercado de trabalho, anualmente, a redução do índice de cárie da população brasileira, principalmente infantil, assim como a crise do modelo assistencial privatista na Odontologia como única fonte de recursos representavam pontos críticos para a atuação profissional no período. (CALADO, 2002) 
No ano de 2001, a CNSB voltou a receber críticas do CRO-SP em sua nota sobre o dia do dentista, em 25 de outubro de 2001. Reforçando a questão sobre o mercado de trabalho, o Conselho Regional apontava a ausência de uma política séria para o setor, o que acarretava dificuldades ao exercício profissional e à população assistida.

A FIO abordou o fato como uma conquista histórica da Odontologia para a categoria e para a população, de uma luta que durou seis anos, além de enfatizar todo o trabalho “de pressão" exercido pela entidade. Noticiou, também, a inclusão do pessoal auxiliar na ESB e a formação a ser realizada.

Já para a coordenação da ATSB, representava a expressão de uma luta das entidades de classe, dos movimentos de crítica organizados, como os Enatespo, além de uma política que beneficiaria a população com o aumento do acesso a serviços odontológicos e a redução da cárie dentária, pautas também oriundas das discussões com o CTC.

Destaca-se que, no período de 1996 a 2001, a mídia voltou a retratar a ausência de uma política nacional de saúde bucal, em matérias das entidades de classe. Na segunda metade da década de 1990, também ocorreram os Congressos de Saúde Bucal Coletiva em articulação com os Enatespo, o que proporcionou integração de mais agentes do campo científico aos eventos, que tinham como principal objetivo ser um espaço de crítica às políticas de saúde bucal. Quanto ao campo político, além da atuação junto ao ministro pela inclusão da Saúde Bucal no PSF, cita-se o PL n 3504/2000 submetido pelo deputado Rubens Bueno, do PPS do Paraná, que buscava determinar a obrigatoriedade dos hospitais de grande porte contarem com cirurgiões-dentistas em seus corpos clínicos. Entretanto, não há documentos que formalizem a articulação da saúde bucal nos distintos níveis de atenção. Outra iniciativa no campo político foi a indicação do deputado Marcos Cintra, do PFL de São Paulo, para a mudança das denominações constantes na Classificação Brasileira de Ocupações (CBO), de auxiliar de Consultório Dentário e de técnico em Higiene Dental para, respectivamente, atendente de Saúde Bucal e técnico em Saúde Bucal (Quadro 15).

Quanto ao planejamento orçamentário no período de 1995 a 2002, observa-se que, nos primeiros cinco anos, houve uma drástica redução, tendo representado menos que $1 \%$ do orçamento do Ministério da Saúde, fato que expressa a ausência de priorização do setor dentro do MS (Tabela 4). 


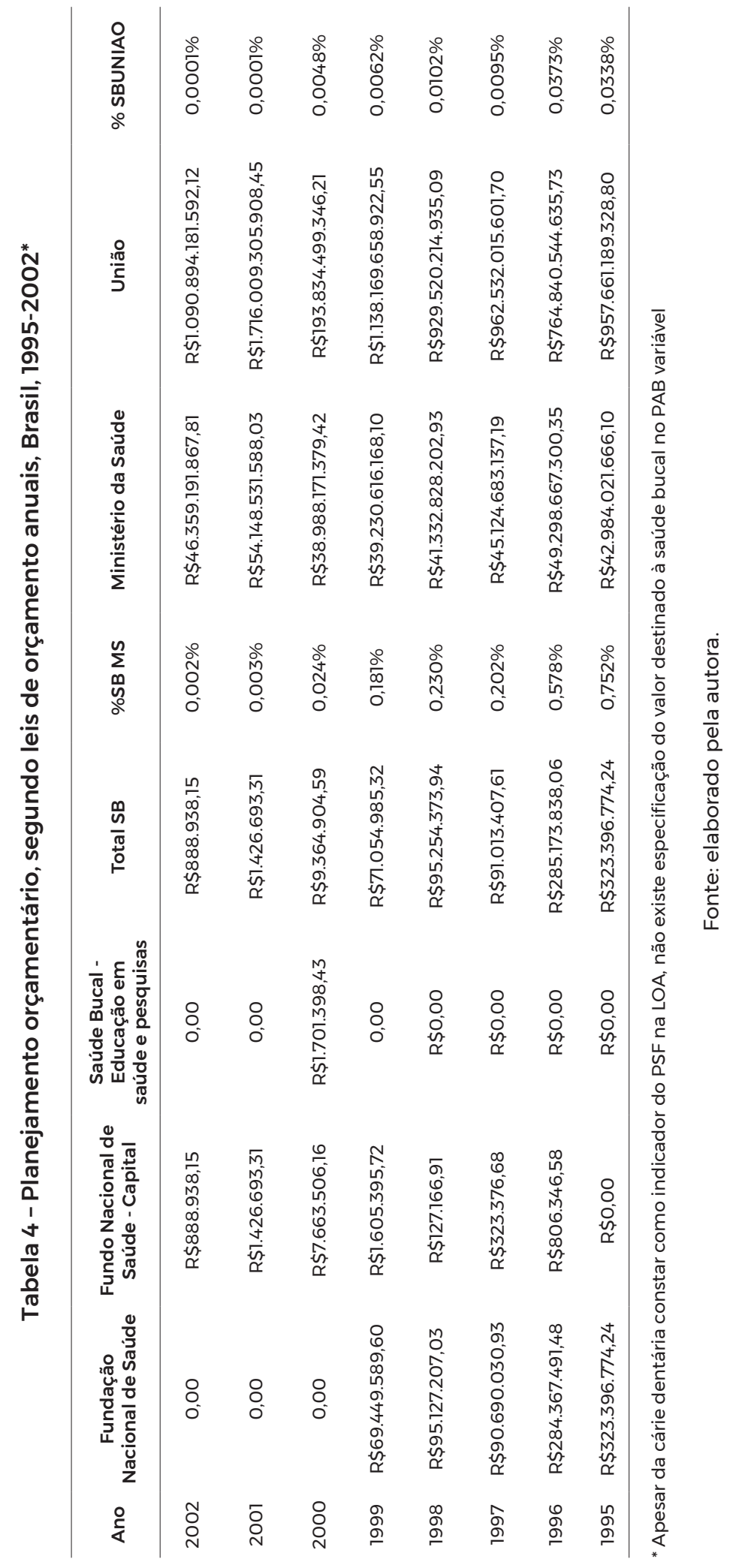

Produção Social da Políticas de Saúde Bucal no Brasil / 169 


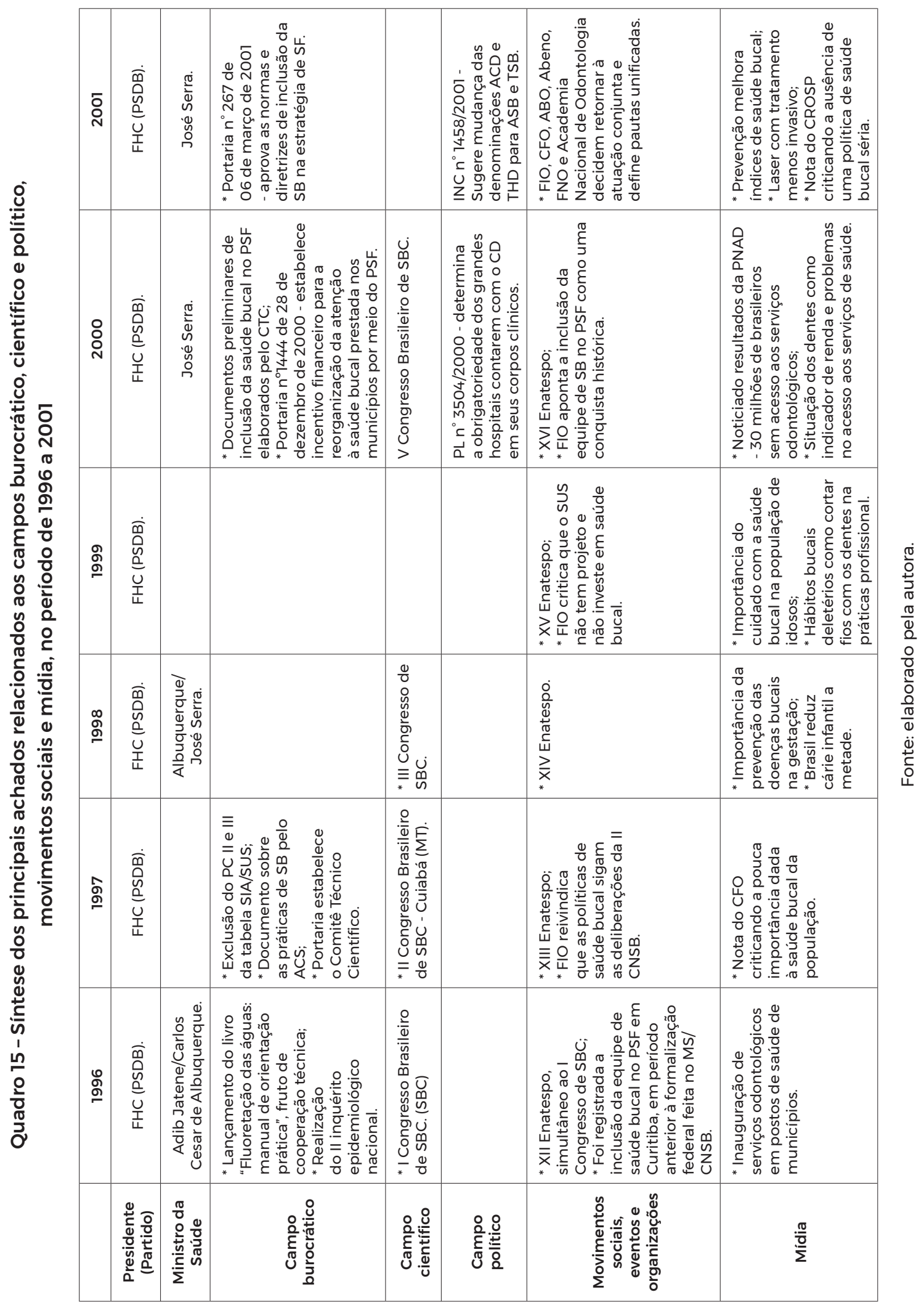




\section{Participantes e disposições que influenciaram a inclusão da equipe de saúde bucal no Programa de Saúde da Família}

Os principais participantes na inclusão da equipe de saúde bucal na agenda foram cirurgiões-dentistas, com exceção do Secretário de Políticas de Saúde, Cláudio Duarte da Fonseca, ${ }^{91}$ que foi um grande interlocutor entre a Área Técnica de Saúde Bucal e a alta administração do Ministério da Saúde. A maioria era do sexo masculino, mas, a partir desta política, observou-se maior inserção das mulheres no espaço de formulação das políticas de saúde bucal, a começar pela própria gestora e também pela presidente da FIO que representou grande apoio na inserção da pauta na agenda do Estado, além das mulheres que eram gestoras de saúde bucal no nível estadual e que também participaram das discussões (Quadro 16).

Alguns membros que participavam dos Enatespo, subespaço contrahegemônico de crítica às políticas nacionais de saúde bucal, também integravam o CTC de assessoramento da coordenadora, como Paulo Capel Narvai e Djalmo Sanzi Souza. A própria gestora participou de alguns eventos e afirmava buscar seguir as recomendações do Enatespo.

Outra instituição fundada para exercer papel semelhante foi a Associação Brasileira de Saúde Bucal Coletiva (Abrasbuco), criada em 1998, em reunião do Enatespo, mas, apesar de alguns membros terem integrado esta Associação, não a reconhecem como partícipe no espaço nacional de formulação das políticas.

As entidades de classe exerceram papel importante na mobilização junto ao campo político, atuando frente a parlamentares e ao ministro da Saúde. A gestora nacional do setor atuou no processo de pactuação no interior do campo burocrático. O CTC desempenhou um papel fundamental na concepção teórica, na articulação com os pressupostos da Atenção Primária à Saúde e na formulação inicial da política. Foram realizadas mudanças entre a proposta inicial do CTC, principalmente relativa à relação ESB $x$ ESF, e aquela aprovada ao final do processo, entretanto, há muitas semelhanças entre a Portaria $n^{\circ} 267$, de março de 2001, e o documento preliminar de outubro de 2000, com os objetivos, atribuições profissionais, responsabilidades institucionais.

A FIO também auxiliava o CFO e outras entidades no direcionamento político, por ter membros com alto capital político com inserção neste campo. Alianças com outras entidades, como a Associação Brasileira de Odontologia, Academia Brasileira

91 Conforme consta em seu currículo lattes, Cláudio Duarte da Fonseca é graduado em Medicina pela Universidade Federal de Pernambuco (UFPE) (1987), mestre em Saúde Coletiva pelo Instituto de Saúde Coletiva da Bahia (2002); especialista em Medicina Preventiva e Social pela UFPE/HC/Inamps (1987); médico sanitarista da Secretaria Estadual de Saúde de Pernambuco. Nos últimos 14 anos, vem participando, em âmbitos municipal, estadual e federal, de projetos de reestruturação de sistemas de atenção à saúde e programas de saúde pública. 
de Odontologia, Federação Nacional dos Odontologistas, Conselhos Regionais de Odontologia, foram realizadas para aumentar a base de apoio para a inclusão da SB no PSF frente ao governo.

A aprovação da inclusão da Odontologia no PSF foi fruto da articulação de membros oriundos do movimento sanitário e contrahegemônicos da Odontologia com as entidades representativas de classe que contaram com uma coordenadora com trajetória no interior do campo burocrático na Área Técnica de Saúde Bucal.

Dentre aqueles que participavam ativamente dos Enatespo, observa-se acumulação média de capital político assim como do burocrático. Quanto ao capital científico, observou-se maior acumulação nos membros do CTC. O presidente do CFO e a presidente da FIO apresentaram acumulação semelhantes dos capitais com atuação no campo político (Figuras 16, 17 e 18).

Dentre aqueles que participavam dos Enatespo, alguns exerciam cargos na gestão estadual, outros na gestão municipal, outro em cargo político ou atuavam no campo burocrático como consultores. Alguns eram professores universitários, tendo exercido cargos na gestão. Observou-se, ainda, que a maioria apresentava capital científico muito baixo, no período, com exceção de dois dentistas, que eram professores e pesquisadores, membros do comitê e de outro agente que participou da discussão da política.

Conforme já referido, o papel exercido pela coordenação da Área Técnica de Saúde Bucal apoiou-se no comitê composto por agentes com inserção no campo científico, assim como o político, através das alianças estabelecidas.

Quanto às tomadas de posição, os membros do CTC defendiam que a inclusão da equipe de saúde bucal modificaria o modelo de atenção praticado, perpassando o processo de trabalho na saúde bucal. Incluíam na agenda a pauta do pessoal auxiliar, oficializando a inclusão da "equipe de SB" e não apenas do dentista no PSF.

Essa discussão, conforme já referido, vinha sendo defendida em reuniões do MBRO, nos Enatespo, assim como na primeira política de saúde bucal de 1989. Além de exercer ações individuais no consultório, os membros da equipe de saúde bucal deveriam desenvolver ações coletivas na comunidade em articulação com os outros profissionais e respeitando as necessidades do território. Ademais, não seguiriam uma lógica de remuneração por procedimento, como nos procedimentos coletivos da década de 1990. A presidente da FIO e seus membros defendiam que a Odontologia era uma especialidade da medicina e que toda a população deveria ter acesso ao atendimento integral. O CFO também mencionou a Odontologia como especialidade médica, mas defendeu, principalmente, a tomada de posição da expansão do mercado de trabalho para o dentista, assim como outras entidades odontológicas como a $\mathrm{ABO}$ e a FNO. 


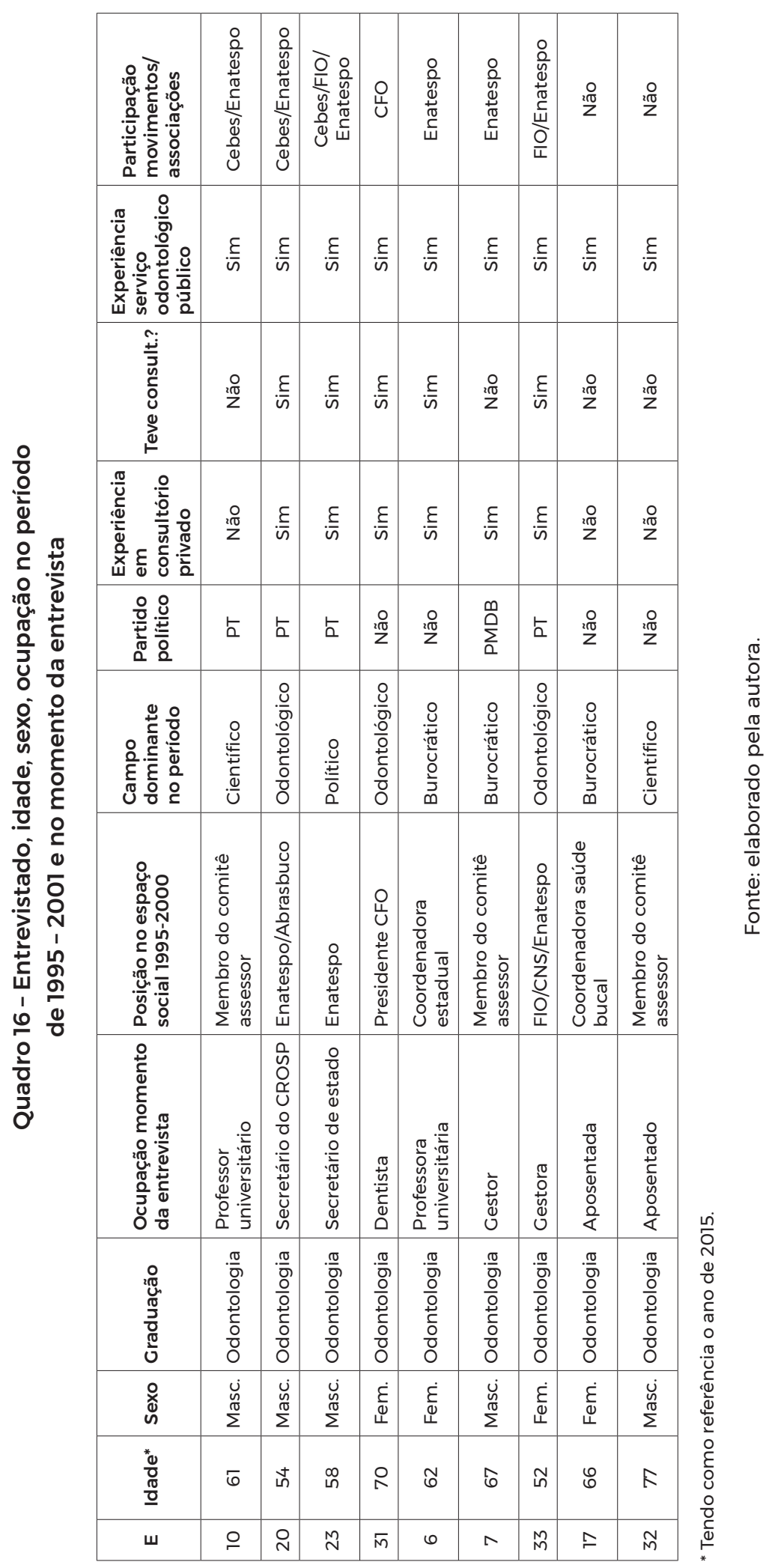


Assim, a inclusão do CD no PSF representava o aumento de postos de traba1ho, muito concentrado em grandes centros urbanos em detrimento do desenho de modelo de atenção concebido por membros do CTC e defendido pelos participantes do Enatespo no qual a mudança realizada assegurava mudanças quanto ao processo de trabalho dos profissionais.

A maioria dos dentistas que participaram da inclusão da equipe de saúde bucal no PSF se identificou como cirurgiões-dentistas em instâncias que exigem apresentação de si ao mundo social como, ao hospedar-se em um hotel, mesmo os bucaleiros, o que pode revelar a preservação da identidade profissional de origem no caso daqueles cuja principal ocupação atual é na Saúde Coletiva.

Havia uma dominância de agentes com maior capital burocrático e político do que científico. O maior volume global de capital estava relacionado aos membros do CTC que participavam dos Enatespo e um membro da FIO (Quadro 17). A coordenação nacional de SB apresentou acumulação global semelhante aos agentes das entidades de classe, mas com composição distinta. O capital predominante na coordenação, era o burocrático, e nas entidades de classe, o político. Os membros do CTC ligados ao Enatespo e os membros da FIO apresentavam trajetória ascendente, concepção de SUS democrático e participaram de movimentos estudantis. Já o presidente do CFO apresentava concepção do SUS distinta, com trajetória ascendente, exercício liberal da profissão e não participou de movimentos estudantis. (Quadro 18)

\section{Quadro 17 - Entrevistado, segundo distribuição e volume dos capitais científico, político e burocrático}

\begin{tabular}{|c|c|c|c|c|c|c|c|c|c|c|c|c|c|}
\hline \multirow[b]{2}{*}{$E$} & \multicolumn{4}{|c|}{ Capital Científico } & \multicolumn{4}{|c|}{ Capital Político } & \multicolumn{4}{|c|}{ Capital Burocrático } & \multirow{2}{*}{$\begin{array}{l}\text { Volume } \\
\text { total }\end{array}$} \\
\hline & $\uparrow$ & $\uparrow \uparrow$ & $\uparrow \uparrow \uparrow$ & $\uparrow \uparrow \uparrow \uparrow$ & $\uparrow$ & $\uparrow \uparrow$ & $\uparrow \uparrow \uparrow$ & $\uparrow \uparrow \uparrow \uparrow$ & $\uparrow$ & $\uparrow \uparrow$ & $\uparrow \uparrow \uparrow$ & $\uparrow \uparrow \uparrow \uparrow$ & \\
\hline 10 & & & & & & & & & & & & & 7 \\
\hline 23 & & & & & & & & & & & & & 6 \\
\hline 20 & & & & & & & & & & & & & 4 \\
\hline 32 & & & & & & & & & & & & & 2 \\
\hline 6 & & & & & & & & & & & & & 3 \\
\hline 31 & & & & & & & & & & & & & 3 \\
\hline 33 & & & & & & & & & & & & & 3 \\
\hline 17 & & & & & & & & & & & & & 3 \\
\hline 7 & & & & & & & & & & & & & 3 \\
\hline
\end{tabular}

Fonte: elaborado pela autora. 
Figura 16 - Agentes participantes do espaço de formulação de crítica das políticas de saúde bucal, segundo capitais burocrático e científico, 1998-2001

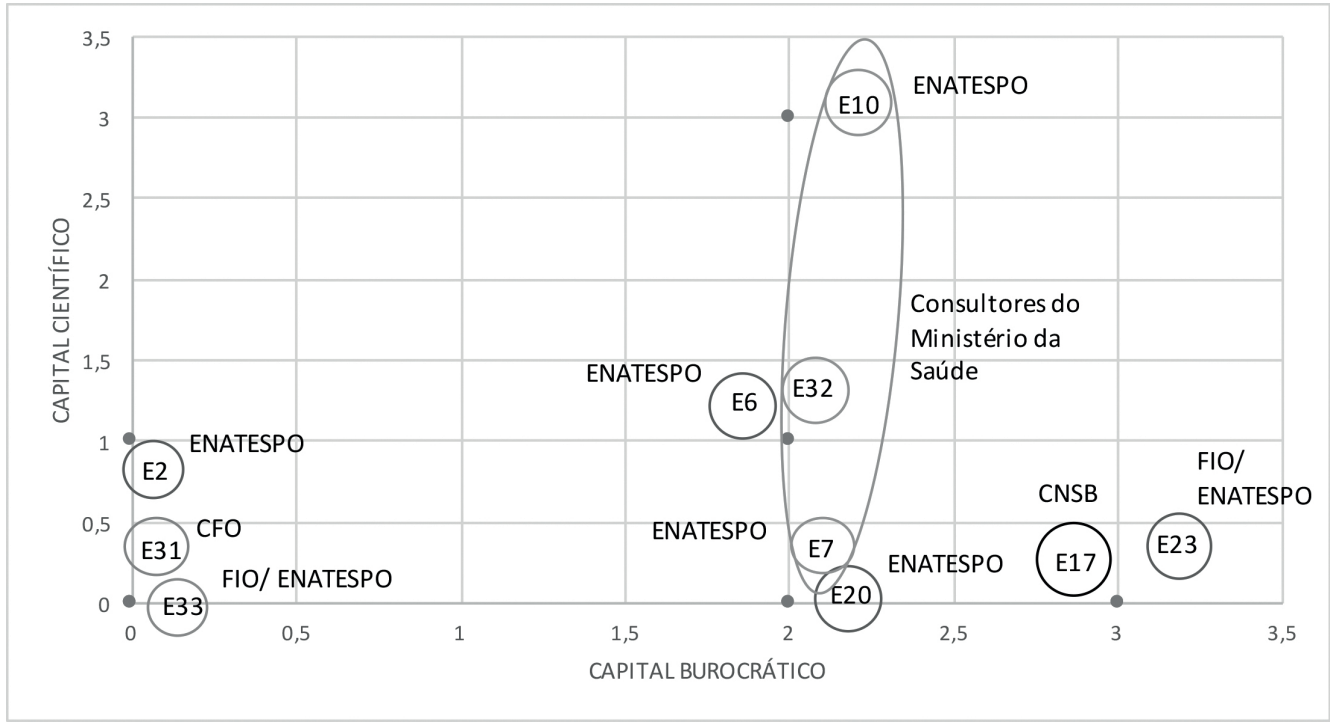

Fonte: elaborado pela autora.

Figura 17 - Agentes participantes do espaço de formulação de crítica das políticas de saúde bucal, segundo capitais burocrático e político 1998-2001

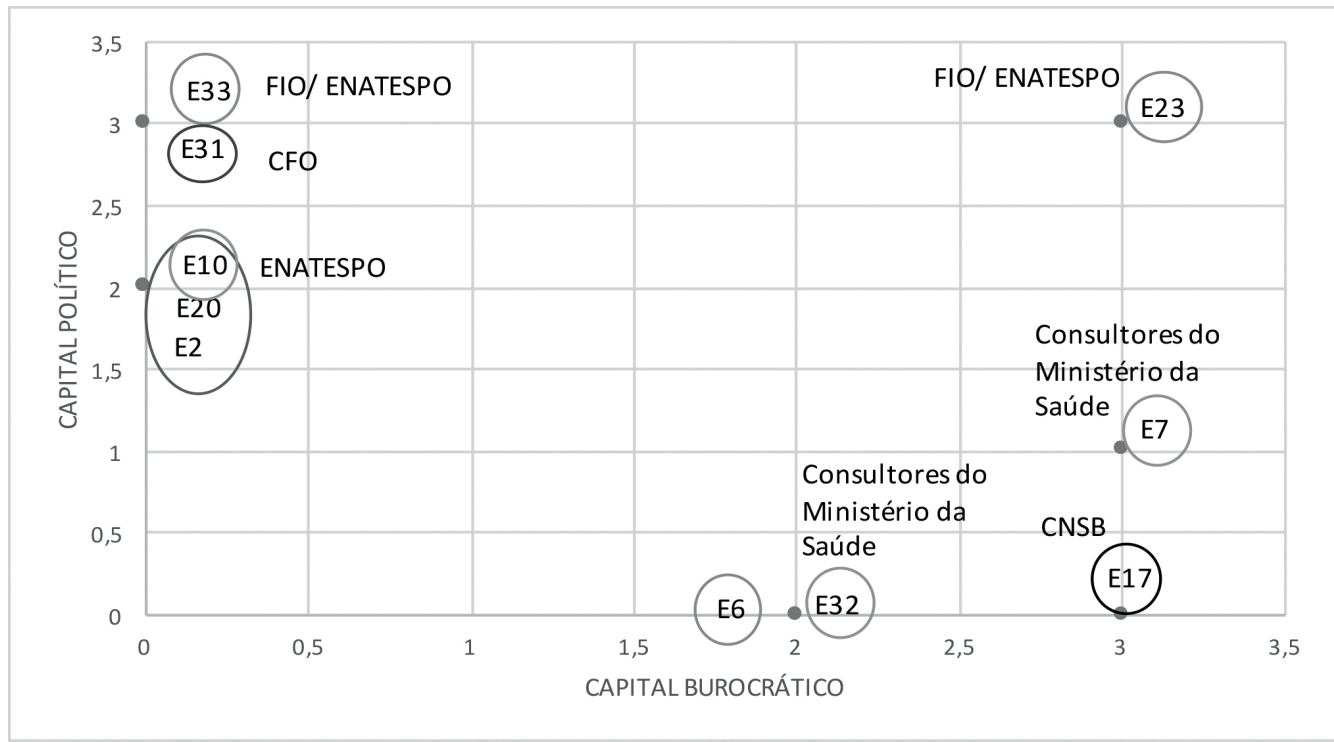

Fonte: elaborado pela autora. 
Figura 18 - Agentes participantes do espaço de formulação de crítica das políticas de saúde bucal, segundo capitais científico e político, 1998-2001

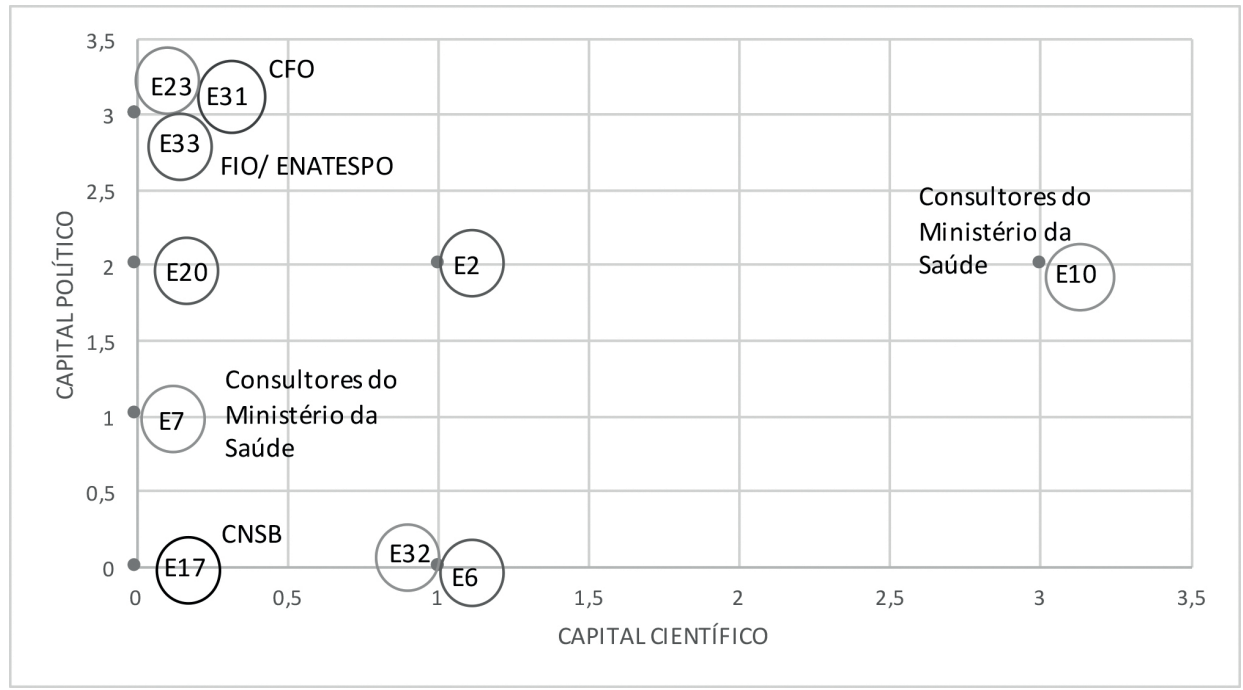

Fonte: elaborado pela autora.

De maneira distinta ao ocorrido no início da década de 1990, os termos mais citados com cinco letras foram "saúde" e "bucal". A Odontologia e dentista estão também nos primeiros planos mostrando o enfoque na profissão. Surgem, em um segundo plano, palavras referentes ao nível político onde as políticas foram articuladas como presidente, governo, político, ministro, ministério. No caso da política de inclusão da Saúde Bucal no PSF, o papel do ministro José Serra foi relevante, com papel importante, e também pelo cenário político nacional representado pelo governo FHC com restrições a um projeto de governo que contemplasse a saúde bucal da população em todas as suas necessidades (Figura 19).

As palavras "movimento", "Abrasbuco”, "conselho", "lideranças”, "conferências”, "entidades”, “coletiva” também surgem como palavras mais referidas pelos entrevistados, o que corresponde à existência dos movimentos, de mobilizações e de pactuações realizados pelas entidades de classe e coordenação de saúde bucal. A Abrasbuco, apesar de ter sido muito referida como uma associação fundada para crítica, não foi considerada partícipe do espaço de formulação dessa política de saúde bucal. 


\begin{tabular}{|c|c|c|c|c|c|c|c|c|c|c|}
\hline \multirow{10}{*}{ 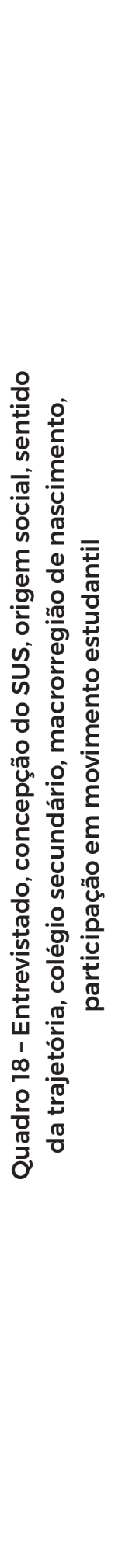 } & 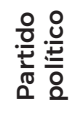 & $\underset{2 \pi}{2 \pi}$ & $\frac{\varepsilon}{n}$ & $\frac{\varepsilon}{i n}$ & $\frac{i \pi}{2}$ & $\frac{\xi}{n}$ & E & $\underline{\xi}$ & $\frac{2}{2 \pi}$ & $\frac{\xi}{n}$ \\
\hline & 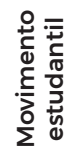 & $\frac{\varepsilon}{n}$ & $\frac{\varepsilon}{\omega n}$ & $\frac{E}{i n}$ & $\frac{0}{2 \pi}$ & $\frac{\varepsilon}{i n}$ & $\stackrel{2}{2 \pi}$ & $\frac{20}{2 \pi}$ & $\frac{E}{i n}$ & $\frac{\varepsilon}{n}$ \\
\hline & $\begin{array}{l}\frac{0}{200} \\
\frac{20}{0} \\
\propto\end{array}$ & $\overline{\bar{n}}$ & $\overline{\breve{s}}$ & $\overline{\bar{n}}$ & $\begin{array}{l}\stackrel{0}{ \pm} \\
\frac{0}{2}\end{array}$ & 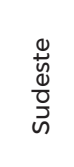 & $\begin{array}{l}\frac{\mathrm{g}}{\Delta} \\
\frac{0}{0} \\
\frac{0}{0} \\
z\end{array}$ & $\overline{\bar{S}}$ & $\overline{\bar{s}}$ & 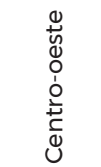 \\
\hline & 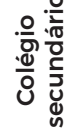 & $\frac{.0}{\frac{.0}{0}}$ & 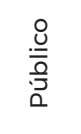 & $\frac{\stackrel{8}{-0}}{\frac{0}{0}}$ & $\frac{.0}{\frac{0}{0}}$ & 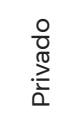 & $\begin{array}{l}\stackrel{8}{0} \\
\frac{0}{0} \bar{a} \\
\square\end{array}$ & $\begin{array}{l}\frac{0}{0} \\
\stackrel{\pi}{\pi} \\
\stackrel{2}{2} \\
0\end{array}$ & $\begin{array}{l}\frac{8}{3} \\
\frac{0}{3} \\
\frac{0}{2}\end{array}$ & $\begin{array}{l}\frac{0}{0} \\
\stackrel{0}{\pi} \\
? \\
\frac{1}{2}\end{array}$ \\
\hline & 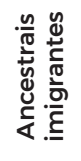 & $\frac{\xi}{n}$ & $\frac{E}{\omega}$ & $\frac{\xi}{n}$ & $\frac{2 \pi}{2}$ & $\frac{20}{2}$ & $\frac{\substack{20 \\
z}}{2}$ & $\frac{\xi}{n}$ & E & $\frac{20}{2 \pi}$ \\
\hline & 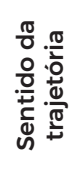 & 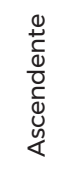 & 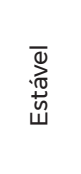 & 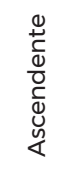 & 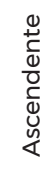 & 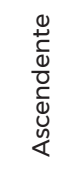 & 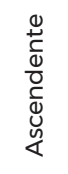 & 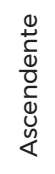 & 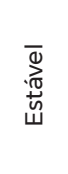 & 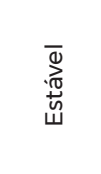 \\
\hline & 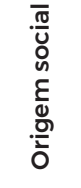 & $\begin{array}{l}\frac{\bar{\sigma}}{\frac{1}{3}} \\
\frac{0}{0} \\
\frac{0}{0}\end{array}$ & $\begin{array}{l}\frac{\pi}{\overline{0}} \\
\frac{\pi}{2}\end{array}$ & $\begin{array}{l}\frac{\bar{\sigma}}{\bar{\sigma}} \\
\frac{0}{0} \\
\square\end{array}$ & $\begin{array}{l}\frac{\bar{d}}{3} \\
\frac{0}{0} \\
\frac{0}{0}\end{array}$ & $\begin{array}{l}\frac{\bar{\sigma}}{\overline{3}} \\
\frac{0}{0} \\
0\end{array}$ & $\begin{array}{l}\frac{\pi}{\overline{0}} \\
\sum \\
\Sigma\end{array}$ & $\begin{array}{l}\frac{\bar{\pi}}{5} \\
\frac{0}{0} \\
\frac{0}{0}\end{array}$ & $\begin{array}{l}\frac{\pi}{\overline{0}} \\
\frac{\pi}{2}\end{array}$ & $\begin{array}{l}\frac{\pi}{\overline{0}} \\
\frac{\pi}{2}\end{array}$ \\
\hline & 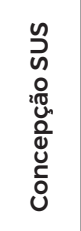 & 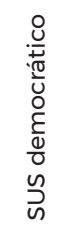 & 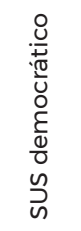 & 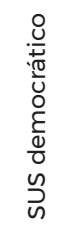 & 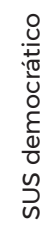 & 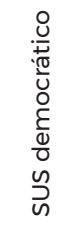 & 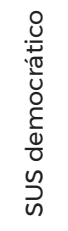 & 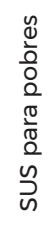 & 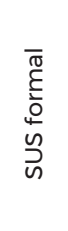 & 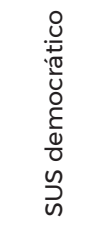 \\
\hline & 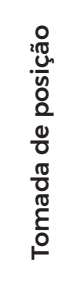 & 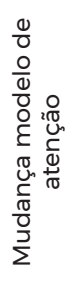 & 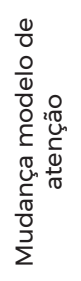 & 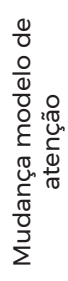 & 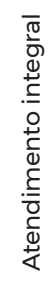 & 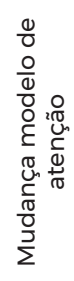 & 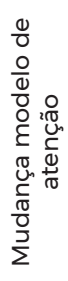 & $\begin{array}{l}\overline{0} \\
\frac{0}{0} \\
\overline{0} \\
\frac{0}{0} \\
0 \\
\frac{0}{0} \\
0 \\
\frac{0}{0} \\
\frac{0}{0} \\
\frac{0}{2}\end{array}$ & 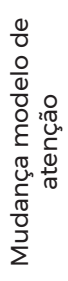 & 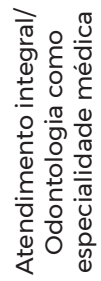 \\
\hline & ш & 6 & n & $\stackrel{\circ}{\circ}$ & 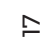 & $\stackrel{\circ}{N}$ & $\stackrel{M}{N}$ & $\bar{m}$ & N & $\stackrel{M}{M}$ \\
\hline
\end{tabular}


Figura 19 - Palavras mais frequentes a partir de cinco, seis, sete, nove, dez e onze letras
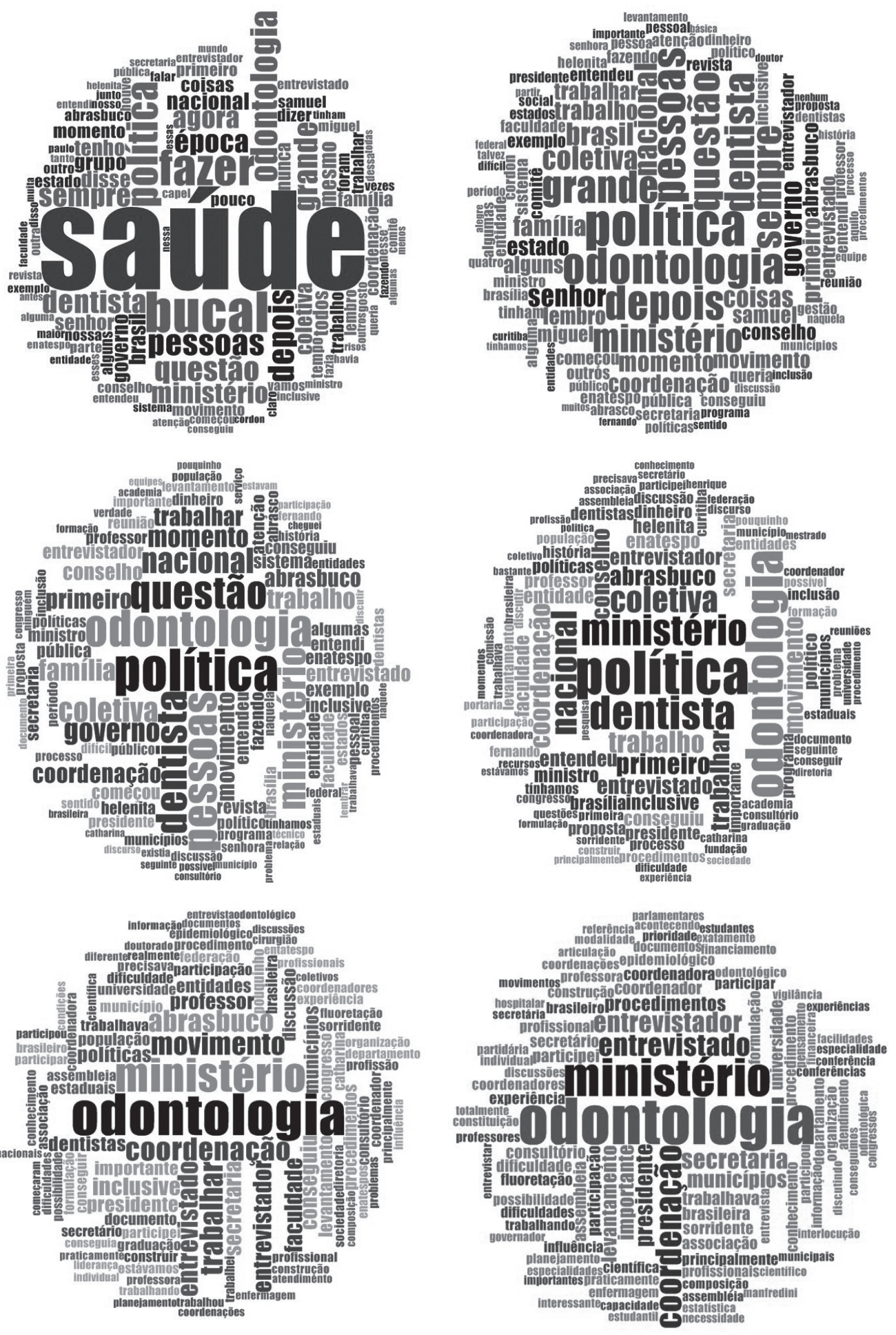

Fonte: elaborado pela autora. 